\title{
A Comparative Study of Locative, Source, Goal and Instrumentive Thematic Relations in English and Sindhi
}

\section{Zahid Ali}

Associate Professor, Faculty of Languages and Literature, Lasbela University fo Agriculture, Water and Marine Sciences, Uthal, Lasbela, Balochistan, Pakistan zahiimahii85@gmail.com

\section{Samiullah Khan}

Assistant Professor, Faculty of Languages and Literature, Lasbela University fo Agriculture, Water and Marine Sciences, Uthal, Lasbela, Balochistan, Pakistan samiluawms@gmail.com

\section{Gul Khanda}

Lecturer, Department of English, Noshki Campus, Sardar Bahadur Khan Women's University, Quetta, Balochistan, Pakistan

Gulsbk100@gmail.com

\begin{abstract}
This research aims to determine the argument/thematic structure of Sindhi verbs. In English and Sindhi, it examines the Locative, Source, Goal, and Instrumentive Thematic Relations. The argument/thematic structure of Locative, Source, Goal, and Instrumentive thematic relations in English and Sindhi has been compared in this study. The data are in oral Sindhi: daily life conversation. The information have been gathered via means of unstructured interviews. Thematic Structure has been applied to analyse Sindhi verb phrases in order to determine the Locative, Source, Goal, and Instrumentive thematic relations in the two languages. The theory of 'Theta Roles and Thematic Relations' (Carnie, 2006; Radford, 2009; Ouhalla, 2010) was employed to analyse the data both theoretically and analytically. It is discovered that Sindhi Locatives, Sources, Goals, and Instrumentives are all connected in some way. In terms of function and importance, they are similar to the English ones. Furthermore, the abovementioned thematic relations in Sindhi are the same as those in English in the written form of the language; they have a set placement/position in a sentence, e.g. initial, middle, or final. However, the semantic/thematic relations in Sindhi are different from those in English in terms of the position/placement in the oral form. Sindhi Sources, Goals, and Locatives are more flexible in terms of placement than English Sources, Goals, and Locatives. Goals and locatives in Sindhi sources are more flexible in terms of location and position than in English; they can be employed at the beginning, middle, or end of sentences.
\end{abstract}

Keywords: thematic relations, argument structure, sources, goals, locatives, instrumentives, English, Sindhi

\section{Introduction}

The structure of a language differs from the other langauge in many ways; some utilise SVO, while others use SOV, VOS, and so on (Veesar, Kadhim \& Baggudu, 2016). The main aim of languages all over the world is to communicate, share, and transfer information from one source to another (Yule, 1996). They cannot, however, have the same structure; each language has its unique structure. The structure differs from one language to the next. The 
structure of Arabic, for example, differs from Hebrew, Sanskrit an other languages as well. The structure of Sindhi (language) is likely to differ from the structure of English (language), and vice versa. The subject, verb, and object (SVO) structure is used in English. Every language has its unique set of forms, sounds, and structural characteristics that distinguish it from others (Chomsky, 1982). Sindhi is one of the subcontinent's most phonologically, morphologically, and structurally diverse languages (Jokhio, 2012; Fahmida, 2012; Zahid, 2016). Almost every language nowadays utilises at least two scripts: its local script and the Roman script. Sindhi, on the other hand, with same vocal form uses three scripts (phonology and lexis): The ArabicSindhi script is being used in Pakistan, the Devanagri script is used in India, and the Roman Sindhi script is often used in Pakistan (used on the internet, mobile phones, and tablets). (Jatly, 2011; Veesar, Z. A., Kadhim, K. A., Shah, S. A. \& Khuhro, R. A., 2016; Tarachandani, 2013). The phonology, morphology, grammar, and especially the Sindhi parts of speech have all been studied on by the authors. Sindhi syntax and semantics, on the other hand, are still overlooked in current linguistics. There is no detailed study of syntax in sindhi available (Pitafi, 2009; Fahmida, 2011; Zahid, 2016). Sindhi is one of the oldest and most widely spoken languages in the subcontinent(Fahmida, 2012; Zahid A., 2016). The major portion syntax, on the other hand, is completely ignored. There is a lot of study on Sindhi grammar, however there is very little work on syntax with perspective of modern linguistics. Adwani (1926) solely focused on Sindhi morphology, grammar, and parts of speech, and put Sindhi syntax on the back burner. Syntax and semantics have been ignored for a long time, or the writers of the past were unaware of these current language words (Veesar, Z.A., Kadhim, K. A. \& Sriniwass, S., 2015). Modern witters, in the same vein, continue to ignore it; Fahmida, 2009; Rahman, 2009; Rashdi, 2009; Pitafi, 2010; Jokhio, 2012; 2013 \& 2014. In the light of the above, the current research aims to determine the thematic structure of Sindhi verbs in terms of Source, Goal, Instrumentive, and Locative Thematic Relations.

\section{Sindhi Verbs}

Verbs are significant in sentences because they show what the sentences are doing. The Argument Structure is determined by a language's verbs, and it depicts the numerous arguments that the verbs take. The verbs of a language assign roles and thematic relationships to arguments (Dowty, 1991; Oltra-Massuet \& Castroviejo, 2014). Verbs can be transitive or intransitive, depending on their nature. Arguments' nature is determined by the character of verbs. A 
transitive verb, as generally known, is a two-place-argument verb, meaning it takes two arguments; an intransitive verb, on the other hand, is a one-place-argument verb (Carnie, 2006; Radford, 2009). The body of a sentence is said to be a verb (Jokhio, 2012a). The verbs demonstrate the actions of sentences. Verbs are classified in languages on the bases of their patterns. According to Jokhio (2012), Sindhi verbs are classified into two categories: auxiliary verbs and main verbs. Sindhi main verbs are classified into two types: regular and irregular. Auxiliaries are also found in tow forms: free auxiliary and linking auxiliary verbs. Verbs in sindhi are derived from imperatives, which are the basic form of Sindhi verbs (Baig, 2006; Zahid A., 2016). According to Baig (2006), Sindhi imperatives are nouns that serve as verbs. He goes on to say that the imperative forms also determine situations like nominative, accusative, and state cases. In Sindhi, the objects of irregular verbs appear indirectly in phrases (Adwani, 1926 \& 1985). Verbs in sindhi form two further types such as transitive and intransitive verbs, which are further subdivided into subtypes (Khoso, 2005; Rashidi, 2007; Agmon, et.al., 2013).

\section{Argument Structure}

The concept of argument structure is employed in modern linguistics to characterise the relationship between the predicate and its arguments. The structure of an argument is made up of both syntactic and semantic elements, with the former presenting participants or arguments and the latter displaying occurrences. Verbs offer thematic roles to the arguments of a phrase (Agmon, 2013). The syntactic sentence structure is identified by the forms of the sentence, that led to the formation of meaning of the sentence (Ackerman, 2013). Structure depicts the hierarchy of arguments (Levin, \& Hovav, 2015; Acua-Faria, Meseguer, \& Carreiras, 2014). The discussion about verb in a sentence is determined by the argument structure. However, thematic structure, is what decides which thematic functions are ascribed to the arguments in a sentence. Arguments are adopted by a verb based on the action or circumstance it expresses; from its meaning. (Haegeman, 1994; 2013). The predicates of the sentences create the argument structure of the verbs; predicates take claims based on the action or state conveyed by the verbs. Two different types of predicates occur: one-place predicates and two-place predicates. Two-place predicates, or transitive verbs, require two arguments to establish the meaning of a phrase. Intransitive verbs are predicates that only take one act in one place. The verbs'/predicate's arguments are realised in sentences through prepositional phrases (PPs) and 
noun phrases (NPs). The argument structure of every predicate identifies the arguments and theta roles they play in the statement. As a result, Rude (1996) of the view that outward justifications are structurally less than applicable arguments, whereas inner arguments are technically higher. (1996). (Fabregas, 2014; Saab, 2015).

The argument pertaining to the verb structure leads to theta roles. The relation of thematic works on theta roles, which are semantic categories (Ouhalla, 1999). The link between syntax and semantics is demonstrated by the Theta- Criterion Theory. The verbs indicate the argument and thematic framework, which are one and the same. Theta roles are assigned to arguments by verbs in a phrase/clause/sentence. Structures of thematic are lexical features that lie within the Projection Principle Theory umbrella. Argument structure, according to Sadler and Spencer (1998), connects syntax and morphology. They term morpholexical operations "meaning-changing" because they affect the semantic content or predicate. Morpho - syntactic procedures change the syntactic presentation of a schema, particularly how it is placed on grammatical links. (Sadler \& Camilleri, 2013; Harley, 2013).

According to Luuk (2009), natural language's predicate/argument form is far more advanced than first-order deductive reasoning. A language has fossils, and according to Jackendoff (1999), a language has five fossils; he refers the structural principles of the text as language fossils. In linguistics, the contrast between predicate and external argument (subject) is well-known. A link between linguistic argument (LA) and language predicate can be established (LP). He offers eleven reasons why LAs are more important in expressions than LPs. In natural language syntax, the linguistic predicate/argument structure has a universal approach. Determiners, possessors, and word order restrictions are all over the place in linguistic arguments, while voiec asepect, mood and tenese, and contrains of word order are all over the place in linguistic predicates (Lu, 2014; Borik, 2014; Adger, 2007).

The argumentative strategy, according to Winterstein (2012) is limited by his inability to handle circumstances in which the internal structure of the items entering the argumentation calculus is directly exploited: psydo "semantic opposition" element such scenario, a finer version of the basic difference technique is required. The level of construction of the arguing purpose is where this susceptibility to structure is found, rather than at the level of the argumentative purpose's formation.Only situations of semantic contrast and rejection of 
anticipation were examined in this study. According to him, at least two other meanings of but are commonly considered: corrective and monadic.

Harley (2013) also investigates external arguments (subjects) as well as the Mirror Principle. He poses the following two research questions: 1) What is the definition of an argument? 2) How are they kept in check? Morphological derivations are syntactic derivations, according to Mirror Principle (Baker, 1985), which means that morphology leads to syntax. External and internal arguments are sandwiched between applied views. The benefited arguemnts are often accompanied by specific verbs obseved in Hiaki. External arguments are introduced via causative verbs, and interior arguments are introduced by applicative morphemes in Hiaki.

On 3 tiers, semantic positions are probed: participant roles, theme roles, and syntactic relationships. Theta allocation of responsibilities based on the clause's phrase structure.The arguments cannot be analysed in isolation; they are linked to other elements and can bear one, two, or three thematic relationships (Lehmann, 2005). Thematic linkages and their explanations make up the theme structure, which is a partial depiction of meaning. (Wechsler, 2005). The languages' arguments are arranged in a hierarchical order: Instrument $>$ Patient/Theme $>$ Place $>$ Agent $>$ Recipient $>$ Experiencer/Goal $>$ (Bierwisch, 2006).

\section{Theta Roles and Thematic Relations}

A theta-role (-role) is a set of thematic relationships associated with a certain point of view (Carne 2007). Thematic linkages and theta roles are exemplified in the following sentence:

\section{$1 \quad$ Sara gave me a book.}

In the first example, the argument 'Sara' is an agent who gives 'a book' to 'me.' The argument 'a book' becomes a source in the statement as it passes from 'Sara' to 'me.' As a result, it's possible to claim that 'Sara' is also the sentence's action source.

'A book,' which is brought to 'me,' is the direct object, or theme of the sentence. According to the logic, 'Me' is the recipient of a book from 'Sara.' As a result, the book stated in the statement helps to support this viewpoint. It is also the sentence's aim; a book goes from 'Sara' to 'me,' indicating the book's final destination. Therefore, keeping this short analysis in view, it can be argued that the example (1) has three arguments (She (NP), a book (NP) and 
me (NP) ) carries three roles of theta (recipient, theme and agent) and five thematic relations (agent, source, theme, recipient and goal).

A semantic link between the argument and the predicate is known as a theme relation (Carnie, 2006). It is verbs that demonstrate theta roles and thematic relationships, as well as their relationship to the sentence's predicate. The semantic roles of participants are described using theta roles and thematic linkages (Radford, 2009; 2013). The following examples demonstrate this.

$2 \quad$ The students bunked the class.

\section{(Agent) (Theme)}

The agent of the example (2) is the argument 'students', which does an action of bunking the class. The second argument 'the class' is a theme goes through a process which is bunked by the students. Carnie (2006) claims that the usage of so-called theme relations is one means of conveying selectional constraints. These are specific semantic phrases that manifest the part of argument performs in relation to the argument. The titles of the participant roles connected with a predicate are theta roles and thematic relations.

\section{Research Methodology}

This study employs the qualitative method (Neuman, 2006; Kumar, 2011). The descriptive and exploratory research designs are used to analyse the data. The study looks at Sindhi verbs' thematic structure in terms of instrumentive, locative, source and goal and aims at their thematic relationships in sentences. It examines and investigates the position, function, and significance of the aforementioned thematic relationships in Sindhi. The study is conducted on the Sindhi spoken form.

The data were gathered from native Sindhi speakers through unstructured interviews so that we could get primary data for the study. The data were collected from the upper Sindh region speakers. The participants were university students, aged between 22-32. The Conveninet sampling technique was applied to collect the data through interviews. The locals (participants) were provided the free and open environment to communicate more freely. They were asked open-ended questions about their education, family, current and previous jobs, goals and objectives, and so on.

\section{Data Analysis}

Carnie proposed the idea of ' Theta Roles and Thematic Relations,' which was used to analyse the English data (2007). This theory serves as the study's theoretical and analytical 
framework. In Sindhi, the source, goal, locative, and instrumentive thematic relations have been investigated. The data are analysed to see how Sindhi verbs relate to the thematic relationships described above. It is also examined to understand how the verbs in Sindhi assign such thematic relationships to arguments. The research also looks for important parallels and differences between English and Sindhi source, goal, locative, and instrumental thematic relations. The current research study examines the Sindhi verbs' Thematic Structure to determine where, when, and how important such thematic relationships are.

\section{Theta-Criterion}

Many linguists and writers believe that each argument has only one theta role, which means that each theta role is assigned to only one argument, and that a single theta role can have multiple thematic relations (Bobaljik, Nevins, \& Sauerland, 2011; Chomsky, 1981 \& 1982; Haegeman, 1994; Carnie, 2007; Radford, 2009; Bobaljik, Nevins, \& Sauerland, 2011).

\section{Thematic Relations}

Theta roles and thematic relations are a link between semantics and syntax that shows the connection between assertions (particiants) and situations. There can be multiple theta roles and thematic relations in a single argument (Davis, 2009). On the other hand, two arguments cannot have the same theta role at the same period (Dowty, 1991). In English, the theta role of agent is explained in cases (3) and (4) under (Carnie, 2006).

3 They called Nani.

$4 \quad$ She spoke Chinese.

The subject of the sentence in example (3) is 'They.' 'They' make a phone call to 'Nani.' In example (4), the character 'She' performs the action of speaking Chinese. They (They) and She (She) both have agent-proto characteristics (Dowty, 1991). As a result, they are the agents of the preceding cases. Let's look at the Sindhi locative, source, goal, and instrumentive thematic relations and analyse them.

\section{Locative Thematic Relations in Sindhi}

Table 1. Locative theta relation in Sindhi example

Example (5)

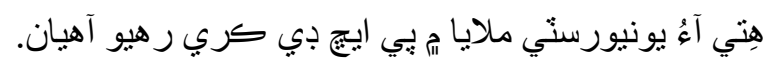

\section{Sentence Sentence \\ Description}


Roman script Hity aaon University Malaya mei PhD kary rahyo aahiyan.

Transliteration Hity=here; aaon=I; University; Malaya; mei=in; PhD; kary=do; rahyo=agreement; aahiyan=am.

Translation I am doing PhD here in University Malay.

The very first argument (NP) 'آ آ $=$ laon=I' is a singular first-person pronoun that can be used in place of a proper noun (a person). This argument completes a task in the sentence: it completes a 'PhD' at the University of Malaya. As a result, because it has an operator thematic relation as well as a nominative case in the sentence, this argument can be considered the sentence's agent. The second argument, 'PhD,' is a proper noun, a phrase indicating a higher degree, and hence cannot execute an action by itself. It is, in fact, the one that anyone can do. This is the argument that the sentence is dealing with (doing). With this in mind, it is possible to argue that this argument is the object or theme that has a theme thematic relation. 'University Malaya mein=in University Malaya' denotes the location where the subject ' $\mathrm{I}$ ' is a $\mathrm{PhD}$ candidate. A noun is usually qualified in a prepositional phrase. The noun in the preceding prepositional phrase is 'University Malaya,' which is a proper noun identifying a location. As a result, this argument is classified as locative.

Table 2 shows a Sindhi example of the locative theta connection.

Example (6)

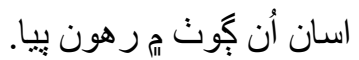

\begin{tabular}{ll}
\hline $\begin{array}{l}\text { Sentence } \\
\text { Description }\end{array}$ & Sentence \\
\hline Roman script & Assan una goth mein rahon paya. \\
Transliteration & $\begin{array}{l}\text { Assan=we; una=that; goth=village; mei=in; rahon=live; } \\
\text { paya=agreement. }\end{array}$
\end{tabular}

Translation We live in that village.

Example 6 shows a noun phrase and a prepositional phrase in the verb phrase "rahoon paya=are living." The agent theta role is played by the noun phrase 'assan = we'. The sentence's prepositional phrase is " una ghoth mein = in that village," indicating the location of the sentence's action.

For plural pronouns, the second person plural argument 'assan $=w^{2}$ ' is used. In the sentence, the prepositional phrase 'una ghoth mein = in that village' is employed as an object 
complement, which completes the statement. It is an object complement, not a direct or proper object, that completes the phrase. The prepositional phrase indicates the area of the subject's location. In the prepositional phrase, the common noun 'goth = village' indicates the place or location where the subject resides. As a result, this argument can be categorized as a locative with the locative theta role and locative thematic relation, as well as the locative case in the phrase.

\section{Source Thematic Relations in Sindhi}

Table 3. Source theta relations in Sindhi example

Example (7)

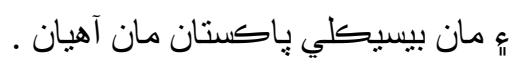

\begin{tabular}{ll}
\hline $\begin{array}{l}\text { Sentence } \\
\text { Description }\end{array}$ & Sentence \\
\hline Roman script & Ain basically maan Pakistan maa aahiyan. \\
Transliteration & Ain=and; basically; maan=I; Pakistan; maa=from; \\
& aahiyan=am.
\end{tabular}

Translation And basically I am from Pakistan.

The verb phrase in Example 7 is 'aahiyan = am,' which includes a noun phrase and a prepositional phrase to consider. The noun phrase is 'مان = maan = I,' and the prepositional phrase is 'Pakistan maan = from Pakistan.' The design of the following case implies that it fits the PP, EPP, and theta-criteria. The argument 'maan = I,' the very first statement, is a firstperson singular. The prepositional phrase 'Pakistan maan = from Pakistan' has 3 functions: it accomplishes a sentence, it indicates the subject's source (identifies origin of subject), and it also suggests the subject's location or location in the sentence. The subject travels from Pakistan to some other place and shows his loction of orgin. It is also locative in the phrase since it reveals the location of the subject. As a result, the proper noun 'Pakistan' can be considered to be both the source and locative of the sentence.

Table 4. Source theta relations in Sindhi example

Example (8)

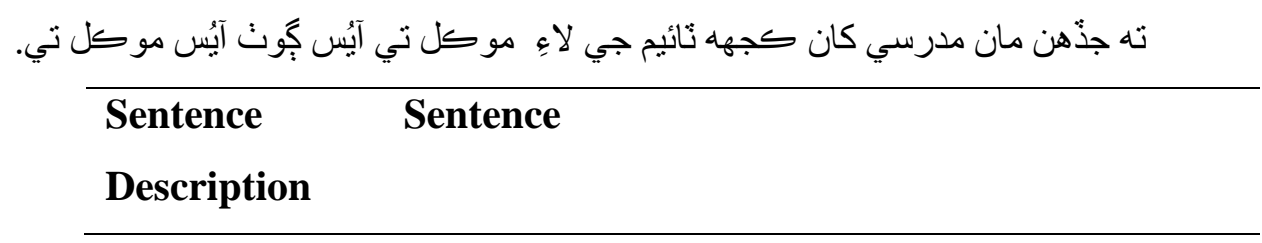




\begin{tabular}{|c|c|}
\hline oman script & $\begin{array}{l}\text { Ta jadahin maan maderse khan kujh time je lai } \\
\text { mokal ty ahyus ghoth aayus mokal ty. }\end{array}$ \\
\hline Transliteration & $\begin{array}{l}\text { Ta=that; } \text { jadahin=when; } \quad \text { maan=I; } \\
\text { maderse=madrasa; khan=from; kujh=some; time; } \\
\text { je=of; lai=for; mokal=leave; ty=on; aayus=came; }\end{array}$ \\
\hline & oth=village aayus=came; mokal=leave ty=on \\
\hline Translation & $\begin{array}{l}\text { o when I came to the village on vacation for a fe } \\
\text { ays from the madaresah. }\end{array}$ \\
\hline
\end{tabular}

Example 8 is represented in table 4 by the verb phrase 'aayus $=$ came', shows two noun phrases 'maan $=$ I' and 'goth $=$ village', and three prepositional phrases 'maderse $\mathrm{khan}=$ from Madersah', 'kujh time lai=for some time', and 'mokal ty = on vacation'. The initial noun phrase, 'maan = I' performs the action of' 'coming' to the village. As a result, this argument is valid and has an agent theta role in the sentence.

In the first prepositional phrase 'maderse khan=from religious school,' the common noun 'maderse=religious school' exposes the sentence's 'source' of action. This argument has an ablative case in the sentence because it demonstrates source in the sentence; the subject (agent) returns home from the madarisa (school). As a result, this argument (maderse=religious school) can be deemed a source of the statement because it serves the role of the source. Furthermore, this argument depicts a location known as a "religious school." As a result, it is possible to say that the sentence carries theta relation of locative theme.

\section{Goal Thematic Relations in Sindhi}

Table 5. Goal theta relation in Sindhi example

Example (9)

$$
\text { أنهيء كان بوءِ وري هليا وينداهون آفيس فا. }
$$

\begin{tabular}{|c|c|}
\hline $\begin{array}{l}\text { Sentence } \\
\text { Description }\end{array}$ & Sentence \\
\hline Roman script & Unhe khan poi wari halya wenda hon office mei. \\
\hline Transliteration & $\begin{array}{l}\text { Unhe=that; khan=from; poi=then; wari=again; halya=go; } \\
\text { wenda=will go; hyon=are; aafice=office; mei=in. }\end{array}$ \\
\hline Translation & Then (we) go back to the office. \\
\hline
\end{tabular}


The table 5 shows a sentence 9 having a verb phrase هليا ويندا هون=halya wenda hon=go/get in/get back/get inside'. This verb phrase carries one argument to review. Its argument is in the prepositional phrase 'آفيس $=$ آن affice mei=in office'.

The argument 'aaffice $=$ office' indicates subject's action's destination/goal. It demonstrates the acts of 'going/getting back' is completed. Thus, the noun 'aaffice $=$ office' in the prepositional phrase 'in the office' shows the goal of the sentence along with goal thematic relation. Afore-mentioned simple noun too indicates subject's placement in the phrase. As a result, the argument 'aaffice $=$ office' can be considered a locative of the phrase, as well as having a locative thematic relation in the sentence. Thus, in above example, the argument 'office' has one theta role of goal and two thematic relation of goal and locative.

The subject of the statement is omitted in the surface structure; we do not know who the subject is unless we check the sentence's basic/deep structure, since this surface structure does not convey a clear subject. In the verb 'wenda=will go,' the phonological inflection 'aa=agreement' shows that the subject is a first person plural masculine (we).

Table 6. Goal theta relation in Sindhi example

Example (10)

$$
\text { و إيس اجي گهر يُوِ بس ماني جو وارو هوندو آهي. }
$$

\section{Sentence Sentence \\ Description}

\begin{tabular}{ll}
\hline Roman script & Wapis achi ghar poi bus maani jo waro hoondo aahy. \\
Transliteration & Wapis=back; achi=come; ghar=home; poi=then; bus=indeed; \\
& maani=meal; jo=of; waro=turn; hoondo=happen; aahy=is.
\end{tabular}

Translation Having come back home then it is my turn to cook meal.

A complex phrase with void elements at the subject and object places is shown in Example 10 in Table 6. The context sentence is used to deduce the concealed subject sentence, which is spoken in passive form.

The phrase 'hondo aahy=is' is displayed in Example 10. It has a prepositional phrase 'maani jo waro=meal turn' and a having clause 'wapis achi ghar=having returned home', which specifies the subject and object positions. As a result, this statement demonstrates how the projection principle and criterion are reflected through reasoning and sentence construction. 
In the prepositional phrase 'maani jo waro=meal turn', the common noun 'maani=meal (dinner)' manifests cooking in the sentence 'dinner.' The word 'maani=meal (dinner)' emphasises the sentence's thematic relation. This is the only argument that is considered and focused on in the statement. The following supplied sentence is to be interpreted as follows: 'having arrived home, I cook meal (dinner)', where 'I' signifies the agent or subject and 'meal' denotes the topic or theme, but 'home' denotes the sentence's location.

In the clause 'wapis achi ghar=come home', the common noun 'ghar=home' is used. The words 'come' and 'cook' denote the subject's purpose, as well as the subject's aim. Therefore, the arguemnt goal oreinted which also sense the role of theme in the given sentence however, it shows the location too. Coming back and cooking meal means shows purpose and theme of the sentences, and it also works as a locative in the given sentence. So, the arguemnt is built that home shows the role of goal along with thematic and locative relation in sentence.

\section{Instrumentive Thematic Relations in Sindhi}

Table 7. Goal theta relation in Sindhi example

Example (11)

$$
\text { أن جو اسان كي جواب ذّيو ايميل جي ذريعي. }
$$

\begin{tabular}{ll}
\hline $\begin{array}{l}\text { Sentence } \\
\text { Description }\end{array}$ & Sentence \\
\hline Roman script & Una jo assan khy jawab dio email je zarie. \\
Transliteration & $\begin{array}{l}\text { Una=that; jo=of; assan=we; khy=have; jawab=answer; } \\
\text { dio=give; email; je=of; zarie= through. }\end{array}$
\end{tabular}

Translation Give us its reply through an email.

In table 7, example 11 offers a verb phrase 'dio=give' with three arguments to discuss (two noun phrases and one prepositional phrase). The noun phrases are 'una jo jawab=its answer/reply' and 'assan khy=us,' whereas the prepositional phrase is 'email je zarie=through an email.'

Direct object of argument is the first argument 'una jo jawab=its answer/reply'. Somebody asked the speaker to answer them through email, as per the speaker. This is the argument that is subjected to the sentence's action: it is being presented. As a result, with the theme theta role and accusative case, this argument is the direct object in the sentence. 
The second argument, 'assan khy=us,' is the possessive form of the second person plural. It shows the ability to hold something. This argument is the sentence's object complement/indirect object so it accomplishes the assertion. The argument 'assan khy=us' shows to whom the answer is given. It is neither the sentence's centre nor its theme. As a result, this argument cannot be considered to reflect the sentence's actual object or theme. However, because it specifies the recipient of the answer (from the second person to the argument 'us'), this argument might be deemed the sentence's goal. As a result, it can be said that it serves as the sentence's goal theta role with goal thematic relation. This argument has an ablative case since it is an indirect object in the statement.

The common noun 'email' does not perform any action in the sentence other than being used as a tool to accomplish the action of 'giving' the answer/reply in the prepositional phrase 'email je zarie=hrough an email.' As a result, in the prepositional phrase, the common noun 'email' is used as an instrument in the sentence to perform the action of replying, and it has both the instrument theta role and an instrumental case.

Table 8. Goal theta relation in Sindhi example

Example (12)

بائيك تي ويندا ها سين بابا سان كذّ سِدو اسكول.

\begin{tabular}{|c|c|}
\hline $\begin{array}{l}\text { Sentence } \\
\text { Description }\end{array}$ & Sentence \\
\hline Roman script & Bike ty wenda haa sein baba saan gad sidho iskool. \\
\hline Transliteration & $\begin{array}{l}\text { Bike; ty=on; wenda=will go; huyaa=were; sein=agreement; } \\
\text { baba=father; saan=with; gad=together; sidho=direct; } \\
\text { iskool=school. }\end{array}$ \\
\hline
\end{tabular}

Translation (We) along with father used to go direct to the school on bike.

Example 12 is shown in Table 8 with the verb phrase 'weend huyaa sein=used to go'. It has two prepositional phrases and one noun phrase. In the statement, the noun phrase 'iskool=school' plays the goal theta role. The prepositional phrases 'bike ty=on the bike' and 'baba saan=with father' include nouns in the sentence that are utilised as instruments to carry out the action.

The initial noun phrase or argument 'iskool=school' is the sentence's object complement because it neither performs nor experiences a sentence action. It's only used to finish a sentence 
and show where the subject is headed. It does not refer to the sentence's theme; instead, it refers to the subject's goal or destination. On the other hand, because it illustrates the sentence's destination or objective, this argument could be deemed the sentence's goal.

The subject is removed from the sentence's surface structure. According to Bur'ro (2004), Sindhi subjects are usually inferred and comprehended from verb inflections. In the verb phrase 'weend huyaa sein=used to go,' the inflection 'sein=agreement' is used to denote the first person plural subject 'assan=we'. The inflection 'sein' is used with the verb phrase to denote the first person plural subject 'we' in Sindhi. As a result, in the Phonetic Form/surface structure of the sentence, the subject of the sentence can be considered to be eliminated.

The argument 'baike=bike' illustrates that it is a sentence instrument in the prepositional phrase 'bike ty=on the bike.' It does not perform or undergo an action; rather, the hidden subject uses it as a tool to carry out the action of 'going' to school. To get to and from the school, the argument 'baike=bike' is used exclusively. As a result, this argument can be thought of as an instrument in the sentence, with an instrument theta role and an instrumental case.

\section{Findings and Discussion}

The data fo the study reveal that Sindhi, like English, uses the same pattern of locative, source, goal, and instrumentive theta relations. 'Sources' are supposed to be at the beginning of an action in a sentence; 'goals' are the ending points or destinations of action; 'intruments' are used to conduct an action; and 'locatives' show places or locations where actions take place in English. Sindhi 'sources,' 'goals,' 'instrumentives,' and 'locatives' show a starting point, a destination, a place or a location, and an instrument of an activity in sentences, just as English. In prepositional and adverbial phrases, English 'instruments,' 'sources,' 'goals,' and 'locatives' are employed as adjuncts (Haegeman, 1994). Adjuncts are always inserted in the middle or at the end of a sentence in English. However, in rare circumstances, such adjucnts can be used at the beginning of a sentence (Carnie, 2006). Sindhi 'sources,' 'goals,' 'locatives,' and instruments, on the other hand, are employed at the end, middle, and beginning of a phrase (Allana, 2010). They do not have any fixed locations; in comparison to English, they are more flexible in terms of placement and position. Agents, themes, and adjuncts (prepositions, adverbs, and adjectives), as we know, have three set locations in sentences: the first, middle, and last (Carnie, 2006). In both written and spoken English, the same pattern of place and position of the argument is used. In English, the positions of arguments are only moved in the 
active and passive forms. Sindhi's written form, which is the standard form of the language, includes defined placements for various arguments at subject, object, and adjunct positions. In the written form of the language, it follows the same pattern of employing locatives, sources, aims, and instrumentives. Sindhi, on the other hand, is distinguished by its spoken form of language, which does not adhere to the place and position of arguments. It employs the abovementioned thematic relations in a variety of sentences. The locations of arguments in spoken Sindhi are violated at the subject and object positions, as well as with their adjuncts. Thematic relations (arguments) in spoken Sindhi are more flexible in their placement in sentences.

We can see many places where spoken Sindhi does adhere to the placement rules for 'sources', 'goals', 'locatives' and 'instruments'; it places them at initial, middle and even at the end of a sentence. There are many places where adverbs follow agents which otherwise should be reverse (Baig, 2006). Example 9 in table 5 shows that an adverb of time 'then' is placed at the initial position of the sentences followed by the rest of constituents of the sentence. Adverbs are to be used after agents and verbs in sentences; may be at middle or final places. It can be seen that the palcement of agents and adverbs is violated in the above mentined example. However, such placement violations do not affect form and meaning of sentences in the spoken Sindhi; it is equally well accepted and grammtically correct.

Example 5 in table 1 shows that the prepositional phrase 'يونيورستي ملايا Malaya mein=in University Malaya' is used before the verb of the sentence. The verb is used at the final positon in the sentence. There are certain places where agents and themes are placed at the middle position of the spoken Sindhi sentence, which must not be placed in the written Sindhi. We can see the example 8, 9,10,11 and 12 where placements of subjects and objects are violated without affecting form and meaning of the sentences. On the other hand, example 11 uses instrument (an email) after the verb (give) which must be used before the verb. Example 12 uses instrument at the initial position of a sentence which must not be used in written Sindhi. Initial position is supposed to be used for agents and middle or final for instruments.

It can be seen that the examples 9,10 and 11 use Null subjects in their surface structure or Phonetic Form (PF) of the sentence. However, the null subjects and objects can be infered, identified or recovered via verbal inflections (INF) and agreement (AGR) (Chomsky, 1982; Haegeman, 1994). It can also be seen that the placement of thematic relations in Sindhi is almost always violated in the spoken form, but followed in the written form. However, the 
interesting finding of the study is that these placement and position violations of sources, goals, locatives and instrumentives do not affect form and meaning of sentence.

As can be seen from the samples and analysis above, different thematic relations have distinct functions to execute. The purpose of locatives, for example, is to place something or to show the position of an action in a sentence. Sources display the action's origin or beginning location. In sentences, goals show the target, destination, or end point of actions. Instruments do not perform functions; instead, agents employ them to carry out actions in sentences. To show the source of action, destination, location, and an instrument used to do something in sentences, the English thematic relations of sources, goals, locatives, and instruments are utilised. The study of the preceding cases reveals that the above-mentioned Sindhi theme linkages function similarly to English. The fundamental difference between Sindhi and English thematic relations is their placement and location; English has a definite placement and location, whereas in Sindhi they can be employed at the beginning, middle, or end of a sentence without impacting structure or meaning.

\section{Conclusion}

Every language, according to Carnie (2006), has a variety of thematic relations; the number of thematic realtions varies from langague to langague. This study aims to describe and analyse the thematic relations and theta roles of locatives, sources, goals, and instrumentives in the Sindhi language. In terms of place/position, functions, and relevance, the Sindhi stated thematic relations are compared to the English ones. The data in this study are analysed using the notion of 'Thematic Relations and Theta Roles' (Carnie, 2006). According to the findings, Sindhi follows a nearly identical pattern of utilising the above-mentioned thematic relations as the English language. In the written form of the language, English and Sindhi sources, aims, locatives, and instrumentives are placed in their established positions (final for English and middle for Sindhi) (standard sentence). In both written and spoken English, the placement/position of such thematic relations follows the same pattern. Sindhi, on the other hand, differs from English in this regard, having a defined spot (i.e. the middle) in written form for the aforementioned thematic relations. In spoken form, it does not follow any defined positions for the above-mentioned thematic relations. Thematic relations in spoken Sindhi are more flexible in terms of location; they can appear at any point in the sentence. 
However, the key finding of the current study is that such errors in the arrangement of thematic relations in spoken Sindhi have no effect on the sentence's form or meaning.

\section{References}

Acuña-Fariña, J. C., Meseguer, E., \& Carreiras, M. (2014). Gender and number agreement in comprehension in Spanish. Lingua, 143, 108-128.

Adger, D. (2007). Review of Arguments and Structure: Studies on the Architecture of the Sentence. Journal ofs Lingua, 117, 1826-1832.

Agmon, N., \& Bloch, Yigal. (2013). Statistics of Language Morphology Change: From Biconsonantal Hunters to Triconsonantal Farmers. Plos One, 8(12). doi: 10.1371/journal.pone.0083780

Allana, G. A. (2010). . سنتيكا سنتي كرامر (Sindhica Sindhi Grammar) (Vol. 1). Karachi, Pakistan: Sindhica Academy, Karachi, Pakistan.

Baker, M. C. (1996). Thematic roles and syntactic structure. In L. Haegeman (ed.), Elements of Grammar: Handbook in generative syntax (pp. 73-137). New York: Springer Science and Business Media.

Baig, M. Q. (2006). سنتي وياكرث(Sindhi Wiyakarn) (Vol. 1). Hyderabad: Sindhi Adabi Board, Jamshoro, Sindh, Pakistan.

Bierwisch, M. (2006). Thematic roles- universal, particular, and ideosyncratic aspects. In B., Ina, S., Matthias, C., Bernard, D. F., Angela (Eds.), Semantic role universals and argument linking (pp. 89-126). Berlin: Walter de Gruyter.

Borik, O., \& Mateu, Jaume. (2014). Argument structure in morphology and syntax: An introduction. Lingua(141), 1-7. doi: 10.1016/j.lingua.2014.01.004

Carnie, A. (2006). A general Introduction (2 ${ }^{\text {nd }}$ ed.). USA.: Blackwell Publishers Ltd.

Chomsky, N. (1981 \& 1982). Some Concepts and Concequences of the Theory of Government and Binding (S. J. Keyser Ed.). London, England: The MIT Press Cambridge, Massachusetts London, England.

Creswell, J. W. (2013). Research design: Qualitative, quantitative, and mixed methods approaches (4 ${ }^{\text {th }}$ ed.). New York: SAGE Publications, Inc. 
Dowty, D. (1991). Thematic proto-roles and argument selection. Journal of Language, 67(3), 547-619.

Ernest, T. (2011). Sindhi boli jo grammar ( $2^{\text {nd }}$ ed.). (A. S. Memon, Trans.; H., Fahmida \& V., Valiram, Eds.). Pakistan: Sindhi Language Authority. (1 ${ }^{\text {st }}$ edition publish in 1872)

Fabregas, A. (2014). Argument structure and morphologically underived nouns in Spanish and English. Journal of Lingua, 141, 97-120. doi: 10.1016/j.lingua.2013.02.011

Fahmida, H. (2012). Different linguistic aspects: Problems of the Sindhi grammar. Sindhi Boli Tahqeeqi Journal, 13-55.

Haegeman, L. (1994). Introduction to Government \& Binding Theory (B. P. Ltd Ed. Second Edition ed.). UK \& USA: Blackwell Oxford UK \& Cambridge USA.

Harley, H. (2013). External arguments and the mirror principle: On the distinctness of voice and v. Journal of Lingua, 125, 34-57.

Jatly, M. (2013). Active Voice, Passive Voice and Impersonal Voice. Sindhi Boli Tahqeeqi Journal, Sindhi Language Authority, Hyderabad, Sindh, Pakistan, 6(2), 7-30.

Jokhio, A. H. (2012a). فعل لازمي . فعل متعدي جو مختصر إياس. Sindhi Boli Tahqeeqi Journal, 3, 41-77.

Kumar, R. (2011). Research methodology: A step by step guide for beginners. USA: SAGE.

Lehman, C. (2005). Participant roles, thematic roles and syntactic relations. Paper presented at the SKY Conference on 'Syntactic Functions-Focus on the Periphery', Helsinki, 1415. 11. 2003.

Levin, B. (2015). Semantics and pragmatics of argument alternations. Linguistics (new in 2015), 1 .

Luuk, E. (2009). The Noun/Verb and Predicate/Argument Structure. Lingua, 119(11), 17071727. doi: 10.1016/j.lingua.2009.02.009

Neuman, W. L. (2006). Social research methods: Qualittitive and quantitative approches. Boston: Pearson Education Inc. Boston.

Ouhalla, J. (1999). Theta Theory. In R. Radojicic (Ed.), Introducing Transformational Grammar (Second ed., pp. 146-179). London: Arnold Publishers.

Pitafi, S. (2009). Evolution of writing grammar in Sindhi (F. Hussain Ed.). Pakistan: Sindhi Language Authority. 
Radford, A. (2009). Introduction to English sentence structure. Cambridge: Cambridge University Press.

Saab, A. (2015). On long-distance theta-role assignment Lingua, 160, 91-126.

Sadler, L., \& Camilleri, M. (2013). Ditransitive predicates and dative arguments in Maltese. Lingua, 134, 36-61.

Tarachandani, N. (2011). بولي "ن. لبيءَ جو فرق. Sindhi Boli Tahqeeqi Journal, Sindhi Language Authority, Hyderabad, Sindh, Pakistan, 78-85.

Wechsler, S. (2005). Thematic structure. In The Encyclopedia of language and linguistics $\left(2^{\text {nd }}\right.$ ed.). Amsterdam: Elsevier.

Winterstein, G. (2012). What but-sentences argue for: An argumentative analysis of but. Lingua, 122(15), 1864-1885.

Veesar, Z. A., Kadhim, K. A., \& Sriniwass, S. (2015a). Establishing the Thematic Structure and Investigating the most Prominent Theta Roles Used in Sindhi Language. International Journal of Applied Linguistics and English Literature, 4(4), 216-230.

Veesar, Z. A., Sriniwass, S., \& Kadhim, K. A. (2015b). A Comparison of Theme Theta Roles in English and Sindhi. Language \& Communication, 2(1), 77-89.

Zahid, A. (2016). Morphosemantic and syntactic analysis of verbs in Sindhi/Zahid Ali (Doctoral dissertation, University of Malaya).

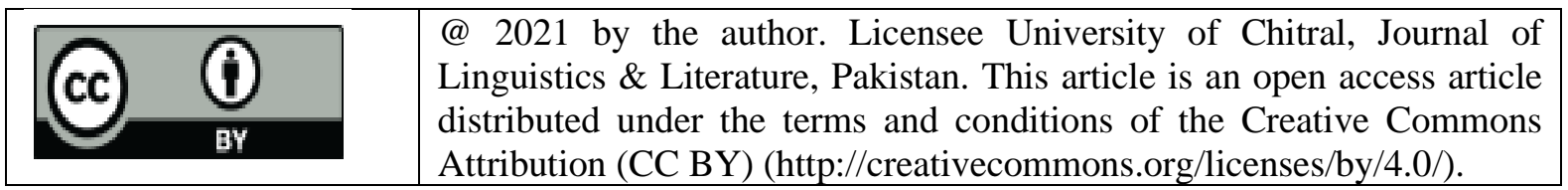

